\title{
Vibration Evaluation of Laminated Hybrid Composite using Finite Element
}

\author{
Y.Seetha Rama Rao, R.Lakshmi, Ch.Siva Ramakrishna, A.Sampath Dakshina Murthy, \\ K.V.SubbaRao
}

\begin{abstract}
Conceptual: the winning studies sample in composite is for the development of composite with carbon fiber. it's far crucial to break down the vibration behavior of composite for powerful usage in severa applications so that they experience with one-of-a-type types of stacking scenario and particular varieties of vibration with numerous stacking succession of filaments. CFRPs have immoderate firmness, and light-weight homes so their packages had been diverse. Be that as it may, CFRP s enjoy the ill effects of a high recurrence vibration. in this paper, numerical examinations have been finished to don't forget vibration behavior of composite overlaid shafts the use of ANSYS 18.1 programming. From the results, the effect of fiber stacking succession at the common frequencies are researched.
\end{abstract}

Catchphrases: pass breed composite, stacking grouping,

\section{ADVENT}

A composite is a cloth comprising of at the least substances which might be artificially made with divergent substances. A composite cloth likewise have to comprise synthetically amazing constituent ranges which may be isolated via way of an unmistakable interface. numerous composite materials are blanketed simplest levels, one is known as the network which frequently encompasses the alternative constituent, that's known as the scattered degree. The properties of the fortification stage (i.E., quantity component, form and length of debris, dispersion and route) signify the homes of the composite. the roles of grid in composite substances are to offer shape to the composite element, cozy the fortifications to the earth, flow burdens to fortifications and durability of material, together with fortifications. The manner of fortifications in composites is to get fine, firmness and different mechanical homes.

The most extensively recognized propelled composites are polymer community composites. these composites contain of a polymer thermoplastic or thermosetting fortified with the aid of fiber (everyday carbon or boron). those materials can be formed into an collection of sizes and styles. They supply super exquisite and firmness along protection from erosion. The purpose inside the lower back of these being most fundamental is their minimum try, immoderate fine and

Revised Version Manuscript Received on 10, September 2019.

Y.Seetha Rama Rao, Department of Mech Engg, GVP College of Engineering, Visakhapatnam, A.P, India.

R.Lakshmi, Department of Mech Engg,GVP College of Engineering,Visakhapatnam, A.P,India.

Ch.Siva Ramakrishna, Department of Mech Engg,Vignan's Institute of Information Technology, Visakhapatnam, A.P, India.

A.Sampath Dakshina Murthy,Department of ECE Vignan's Institute of Information Technology,Visakhapatnam, A.P, India.

K.V.SubbaRao , Department of Mech Engg,Vignan's Institute of Information Technology,Visakhapatnam, A.P, India. modular research, loose vibration.

simple assembling standards. most in the primary carried out framework materials are polymeric. via and large the mechanical houses of polymers are insufficient for some number one capabilities. in particular their incredible and firmness are low contrasted with metals and pottery. these problems are crushed with the aid of strengthening particular substances with polymers. except the dealing with of polymer lattice composites want no longer include high weight and would not require immoderate temperature. Likewise hardware's required for assembling polymer lattice composites are extra sincere. for this reason polymer framework composites grew speedy and earlier than prolonged wound up widely identified for auxiliary applications.

half and half composites are similarly advanced composites whilst contrasted with conventional FRP composites. half and halves will have a couple of strengthening stage and a solitary lattice degree or unmarried fortifying degree with severa community degrees or one-of-a-type fortifying and numerous framework levels. they have got better adaptability at the same time as contrasted with specific fiber reinforced composites. typically it consists of a excessive modulus fiber with low modulus fiber. The excessive-modulus fiber gives the firmness and burden bearing traits, at the equal time as the low modulus fiber makes the composite extra harm tolerant and maintains the fabric fee low. The mechanical properties of a half and half of of composite can be fluctuated through converting quantity share and stacking grouping of diverse uses.

\section{free vibration}

unfastened vibration implies the motion of a structure with out a effective outdoor powers or bolster movement. The motion of hetero 2 nd request differential condition of movement with out damping is introduced in situation 1 .

$$
m \frac{d^{2} u}{d t^{2}}+k a=0
$$

Free vibration is initiated by disturbing the system from its static equilibrium position by imparting the mass some displacement $\mathrm{u}(0)$ and velocity $\mathrm{u}(0)$ at time zero, defined as the instant the motion is initiated : $\mathrm{u}=u(0), \stackrel{\mathrm{u}}{=}=\stackrel{\mathrm{u}}{(}(0)$ So, solution to the equation is obtained by standard methods:

$$
\mathrm{U}(t)=u(0) \cos \omega_{n} t+\frac{\dot{u}(0)}{\omega n} \sin \omega_{n} t
$$


Where natural circular frequency of vibration in unit radians per second:

$$
\omega_{n}=\sqrt{\frac{k}{m}}
$$

Natural frequency of vibrations is denoted by

$$
f_{n}=\frac{\omega_{n}}{2 \pi} H z
$$

The equation of motion of a discredited un-damped elastic structure undergoing small deformation can be expressed as: $[M]\{\ddot{u}\}+k\{u\}=0$ Eigen vectors can be determined from the following equation: $|[D]-\lambda[I]|=0$

Where $[D]=$ Dynamic matrix, $[k]=$ Stiffness matrix, $[M]=$ Mass matrix

$$
[D]=[M]^{-1}[k], \text { Eigen vector } \lambda=\omega^{2}
$$

In this investigation eight nodded iso-parametric plate bending element has been chosen to discretize the plates. The element is capable of incorporating the transverse shear deformation through the implementation of first order shear deformation theory as applicable to composites.

The element stiffness matrix can be expressed as

$$
\begin{aligned}
& :[k]=\iint[B]^{T} \cdot[D] \cdot[B] d x \cdot d y \\
& \text { The consistent mass matrix is expressed as } \\
& {[M]=\iint[N]^{T} \cdot[p] \cdot[N] d x \cdot d y}
\end{aligned}
$$

\section{RELATED WORKS}

Severa creators implemented exquisite techniques for the past numerous years for spotlight extraction. This vicinity will talk approximately the techniques utilized by specific creators.

Prasad et al. Introduced exploratory and numerical effects on the vibration of woven fiber metal protected plates at diverse restriction situations. A restrained component (fe)based definition is constructed up for the plate the usage of the number one request reissner-mindlin speculation, consisting of the two strands and metals of numerous material homes in interchange layers [1]. Mishra et al. Displayed an exploratory examination of the everyday recurrence of woven fiber composite plate. The impact of numerous limit conditions(bcs) in conjunction with loose-unfastened, cantilever, essentially upheld, and completely cinched have become given and checked out aftereffects of past investigations in writing any vicinity to be had [2].

Mohanty et al. Examined a restricted thing version for a composite plate with delamination of a woven fiber glass with epoxy. The frequencies of vibration decline with increment of the delamination region in woven fiber vibration characteristics of woven fiber glass/epoxy delaminated doubly bended composite forums in a warm domain depending at the limited aspect technique. First-request shear misshapening speculation is utilized for a composite shell model with affiliation of mid-aircraft strip delamination at discretionary areas. The ordinary frequencies of loose vibration of woven fiber composite shells decline with a variety in temperature and delamination sector because of lower of solidness for all overlays [4]. Faroughi et al. Built up an iso-geometric approach depending on higher request clean non-uniform rational $b$-splines (nurbs) premise capacities for the pressure, vibration and electricity exam of
Finite Element Analysis composite plates [3]. Panda et al. Decided the unfastened

included composites. Lightweight fabric, as an example, frp has been notably carried out in aeronautical, maritime, and car programs; anyhow, the detriment of this framework is that frps are defenseless in opposition to impact harm. To triumph over these dangers, an change mixture of substances has been applied (aluminum and frp). Additionally, while a composite cloth is uncovered to high temperature or unfavourable situation, it affects the mechanical and bad homes. One approach to improve the material awesome, even as supplying to such a situation, is to overlay each the surfaces of the composite material, with a layer of metal material [5].

Biswal et al. Researched hygrothermal outcomes with the expectancy of complimentary vibration of woven fiber glass/epoxy blanketed composite barrel shaped shallow shells. Numerous trials are led for barrel formed shell forums with diverse ebb and flow proportions and overlay association underneath numerous restrict situations uncovered to uniform difference in temperature and dampness focuses for correlation with fem effects. It's miles visible that the not unusual frequencies of unfastened vibration of covered composite shells lower with increment in uniform temperature and dampness attention due to decrease of the firmness and increments with diminishing the arch proportions [6].

Chandrashekhar et al. Carried out nonlinear vibration studies the usage of a $\mathrm{c} 0$ anticipated strain brought restricted component plate version depending on reddy's third request speculation. Monte carlo simulation with latin hypercube sampling method is implemented to get the difference of hetero and nonlinear ordinary frequencies of the plate because of irregularity in its material houses. It's miles determined that the nonlinear frequencies show expanding non-gaussian chance thickness artwork with growing adequacy of vibration and show double tops at immoderate sufficiency proportions. This careworn nature of the scattering of nonlinear eigenvalues is also exposed in eigenvalue affectability exam [7]. Madhukar et al. Exhibited an utilization of the meshfree commonplace neighbor galerkin technique for the static and vibration studies of plates and overlays. The consistency and meeting of solutions for avoidance and stresses have been examined via changing request of gauss quadrature and the quantity of hubs. It's been seen that awesome assembly of consequences is obtained with increment within the quadrature focuses and hubs [8].

Dongdong et al. Focused loose vibration research of dainty plates utilizing hermite duplicating detail galerkin art work loose approach with sub-vicinity balanced out accommodating reconciliation. Inside the hrk estimate each the deflectional and rotational degrees of opportunity at a conventional vicinity thing are considered to construct the bet of the critical avoidance variable with the resource of at the identical time forcing the imitating or consistency situations on the redirection and pivots [9]. Zhou et al. Proposed a replicating portion molecule method (rkpm) is applied to dissect the characteristic frequencies of euler-bernoulli shafts absolutely as kirchhoff plates to foresee the limited vibration

Published By: 
reactions of protected pipelines because of longitudinal voyaging waves. Two precise strategies, lagrange multipliers simply as change method, are carried out to authorize fundamental restrict conditions [10].

Rajesh et al. Explored banana and sisal fiber haphazardly organized fortified polymer composite for common recurrence and damping issue. Impact of numerous weight charge on banana, sisal and skip breed composite are tested. It's miles found $1 / 2$ composite has maximum severe normal recurrence contrasted with other type composites. Because it expands the solidness of the cloth. Furthermore, half weight composite changed into handled with sodium hydroxide. The outcome demonstrates that substance treatment builds the modulus of the fabric and expands the solidness of the composite [11]. Kumara et al. Analyzed the vibration attributes of bagasse-banana fiber half and half composite. The composite is created thru hand layup method and its vibration residences are contemplated in which vibration take a look at was accomplished through utilizing obstruction strain sensors to distinguish the dynamic pressure in the composite plates [12].

\section{PROPOSED TECHNIQUE}

\section{A. Finite thing studies}

Restrained thing calculations have changed right into a beneficial asset that allows you to dissect and resolve a big scope of designing problems. One of the most testing and most famous enterprise usually useful software applied in limited issue exam is the commercial organization constrained factor programming "ansys". The confined element research of covered composite in this work is finished utilizing the product ansys 18.1 apdl. Limited elements version and solution manner the version of the cantilever fiber reinforced polymer composite plate having measurements 2 hundred $\mathrm{mm}$ (duration) $\times 20 \mathrm{~mm}$ (width) turned into evolved.

The plate thickness " $t$ " become taken to be reliant on the fiber/network combination implemented in the laminas that made the plate. The handle thickness for composite plates changed into taken as $0.5 \mathrm{~mm}$ for my part. The plate come to be tested as a aircraft quarter in ansys 18.1 and after that in shape the use of 8 noded quadrilateral shell factor (shell281). The shell281 issue is suitable for breaking down slim to decently thick shell structures. The component has 8 hubs with six stages of opportunity at every hub: interpretations in the $\mathrm{x}, \mathrm{y}$, and $\mathrm{z}$ tomahawks, and turns about the $\mathrm{x}, \mathrm{y}$, and z-tomahawks. The exactness in demonstrating composite shells making use of those components is run by using manner of the number one request shear disfigurement hypothesis (fsdt) in which the transverse shear strain is notion to be normal through the thickness of the shell. The composite turned into fixed on the edge having size of 20 $\mathrm{mm}$. In order to complete the modular exam to get the mode shapes and not unusual recurrence. The rectangular lanczos mode extraction method became applied. An apdl code turned into composed to finish the above strides in fea and to do encourage parametric exam. Evaluation of the 9 flexible moduli to determine the composite fabric is orthotropic fabric. By using comprehending the below situations we get the estimations of flexible constants of composite. When you consider that we apprehend the flexible constants of fiber and grid materials are implemented to parent the characteristics for required composite material is as consistent with the subsequent.

Longitudinal Young's modulus, $\mathrm{E}_{11}$

Transverse Young's modulus, $\mathrm{E}_{22}, \mathrm{E}_{33}$

Major and Minor Poisson's ratio, $v_{12}, v_{23}, v_{13}$

In-plane shear modulus, $\mathrm{G}_{12} \mathrm{G}_{23} \mathrm{G}_{13}$

By using strength of materials approach

$\mathrm{E}_{\mathrm{f}}=$ Elastic Modulus of Fiber

$\mathrm{E}_{\mathrm{m}}=$ Elastic Modulus of Matrix

$\mathrm{G}_{\mathrm{f}}=$ Shear Modulus of Fiber

$\mathrm{G}_{\mathrm{m}}=$ Shear Modulus of Matrix

$v_{\mathrm{f}}=$ Poison's Ratio of Fiber

$v_{\mathrm{m}}=$ Poison's Ratio of Matrix

$\mathrm{V}=$ Fiber Volume Fraction

$\mathrm{V}_{\mathrm{m}}=$ Matrix volume fraction

$\mathrm{D}_{\mathrm{f}}=$ Density of Fiber

$\mathrm{D}_{\mathrm{m}}=$ Density Ratio of Matrix

Longitudinal young's modulus

$\mathrm{E}_{11}=\mathrm{E}_{\mathrm{f}} * \mathrm{~V}+\mathrm{E}_{\mathrm{m}} *(1-\mathrm{V})$

Transverse young's modulus

$\mathrm{E}_{22}=\mathrm{E}_{\mathrm{m}} *\left(\mathrm{E}_{\mathrm{f}}+\mathrm{E}_{\mathrm{m}}+\left(\mathrm{E}_{\mathrm{f}}-\mathrm{E}_{\mathrm{m}}\right) * \mathrm{~V}\right) /\left(\mathrm{E}_{\mathrm{f}}+\mathrm{E}_{\mathrm{m}}-\left(\mathrm{E}_{\mathrm{f}}-\mathrm{E}_{\mathrm{m}}\right) * \mathrm{~V}\right)$

Major poison's ratio $\mathrm{v}_{12}=\mathrm{v}_{\mathrm{f}} * \mathrm{~V}+\mathrm{v}_{\mathrm{m}} *(1-\mathrm{V})$

Minor poison's ratio

$\mathrm{v}_{23}=\mathrm{v}_{\mathrm{f}} * \mathrm{~V}+\mathrm{v}_{\mathrm{m}} *(1-\mathrm{V}) *\left(1+\mathrm{v}_{\mathrm{m}}-\mathrm{v}_{12} * \mathrm{E}_{\mathrm{m}} / \mathrm{E}_{11}\right) /\left(1-\mathrm{v}_{\mathrm{m}} \wedge 2+\mathrm{v}_{\mathrm{m}} * \mathrm{v}_{12} *\right.$

$\left.\mathrm{E}_{\mathrm{m}} / \mathrm{E}_{11}\right)$

Inplane Shear Modulus

$\mathrm{G}_{12}=\mathrm{G}_{\mathrm{m}} *\left(\mathrm{G}_{\mathrm{f}}+\mathrm{G}_{\mathrm{m}}+\left(\mathrm{G}_{\mathrm{f}}-\mathrm{G}_{\mathrm{m}}\right) * \mathrm{~V}\right) /\left(\mathrm{G}_{\mathrm{f}}+\mathrm{G}_{\mathrm{m}}-\left(\mathrm{G}_{\mathrm{f}}-\mathrm{G}_{\mathrm{m}}\right) * \mathrm{~V}\right)$

$\mathrm{G}_{23}=\mathrm{E}_{22} /\left(2 *\left(1+\mathrm{v}_{23}\right)\right)$

Density of composite Den $=\mathrm{D}_{\mathrm{f}} * \mathrm{~V}+\mathrm{D}_{\mathrm{m}} *(1-\mathrm{V})$

We assume the material is transversely isotropic material $\mathrm{E}_{33}=\mathrm{E}_{22}=$ Transverse young's modulus $\mathrm{v}_{13}=\mathrm{v}_{12}=$ Axial poison's ratio for loading in $\mathrm{x}$ direction $\mathrm{G}_{13}=\mathrm{G}_{12}=$ Axial shear modulus i.e shear stress parallel to the fibers.

\begin{tabular}{|l|l|l|}
\hline $\begin{array}{l}\text { Elastic } \\
\text { Constants }\end{array}$ & Carbon/epoxy & Basalt/epoxy \\
\hline E11 & $42 \mathrm{e} 09$ & $19.466 \mathrm{e} 09$ \\
\hline E22 & $5.1466 \mathrm{e} 09$ & $4.7165 \mathrm{e} 09$ \\
\hline E33 & $5.1466 \mathrm{e} 09$ & $4.7165 \mathrm{e} 09$ \\
\hline V12 & 0.296 & 0.3226 \\
\hline V23 & 0.26675 & 0.422 \\
\hline V13 & 0.296 & 0.3226 \\
\hline G12 & $2.81146 \mathrm{e} 09$ & $1.674 \mathrm{e} 09$ \\
\hline G23 & $1.8142 \mathrm{e} 09$ & $2.138 \mathrm{e} 09$ \\
\hline G13 & $2.81146 \mathrm{e} 9$ & $1.674 \mathrm{e} 09$ \\
\hline
\end{tabular}

desk 1 with the aid of calculating we get 9 elastic constants of carbon/epoxy and basalt/epoxy

Then the shell layup is accomplished and the modeling of composite layup is executed using rectangle dimensions $200 \mathrm{~mm} \times 20 \mathrm{~mm}$. next we pass for meshing of the version. Meshing is performed by using deciding on quality mesh globally and meshing is done in the course of the composite. After Meshing boundary conditions are applied i.e cantilever circumstance is carried out. so that it's far constant at one give up. model analysis is achieved to get the herbal frequency and Mode shapes of the version.

Published By: 


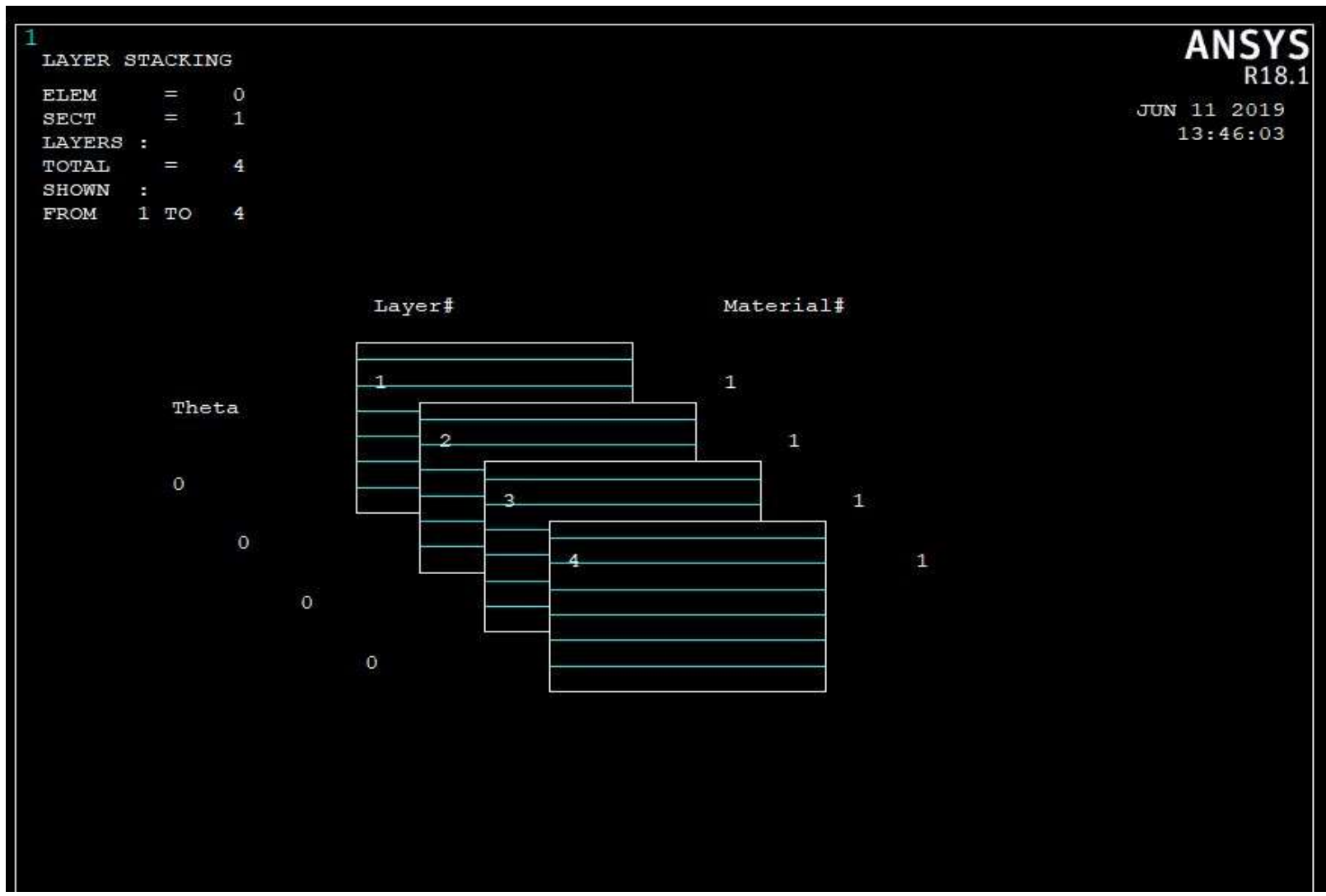

Fig. 1 Lamination angles

\section{RESULT ANALYSIS}

A. natural Frequency using ANSYS 18.1

model evaluation has been achieved to get herbal fibers in composite samples in Ansys 18.1 APDL software. Hybrid basalt and carbon fiber composites are modelled and evaluation is performed as manner defined in previous session.

frequency and Mode shapes of different stacking sequence of
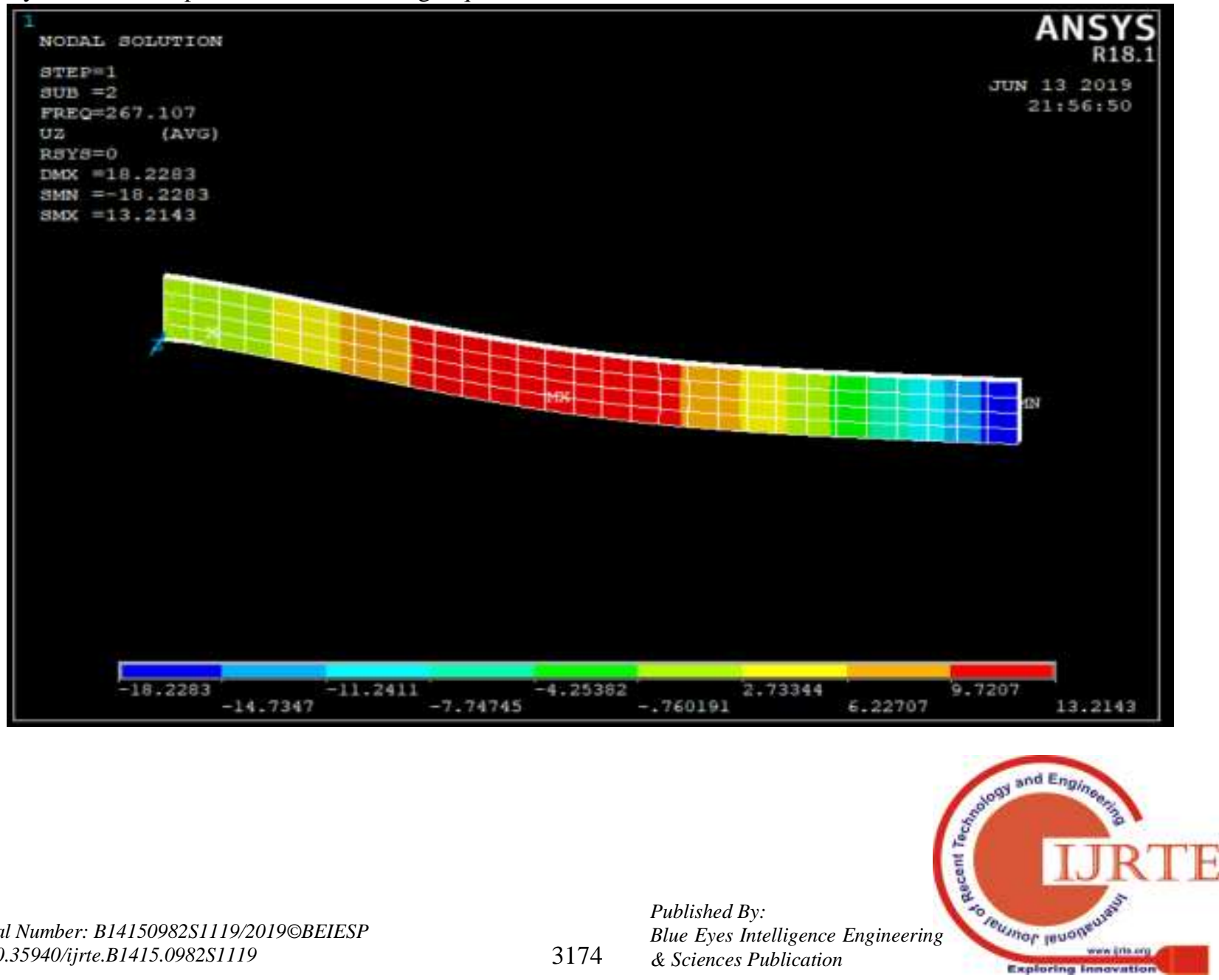
International Journal of Recent Technology and Engineering (IJRTE) ISSN: 2277-3878, Volume-8, Issue-2S11, September 2019
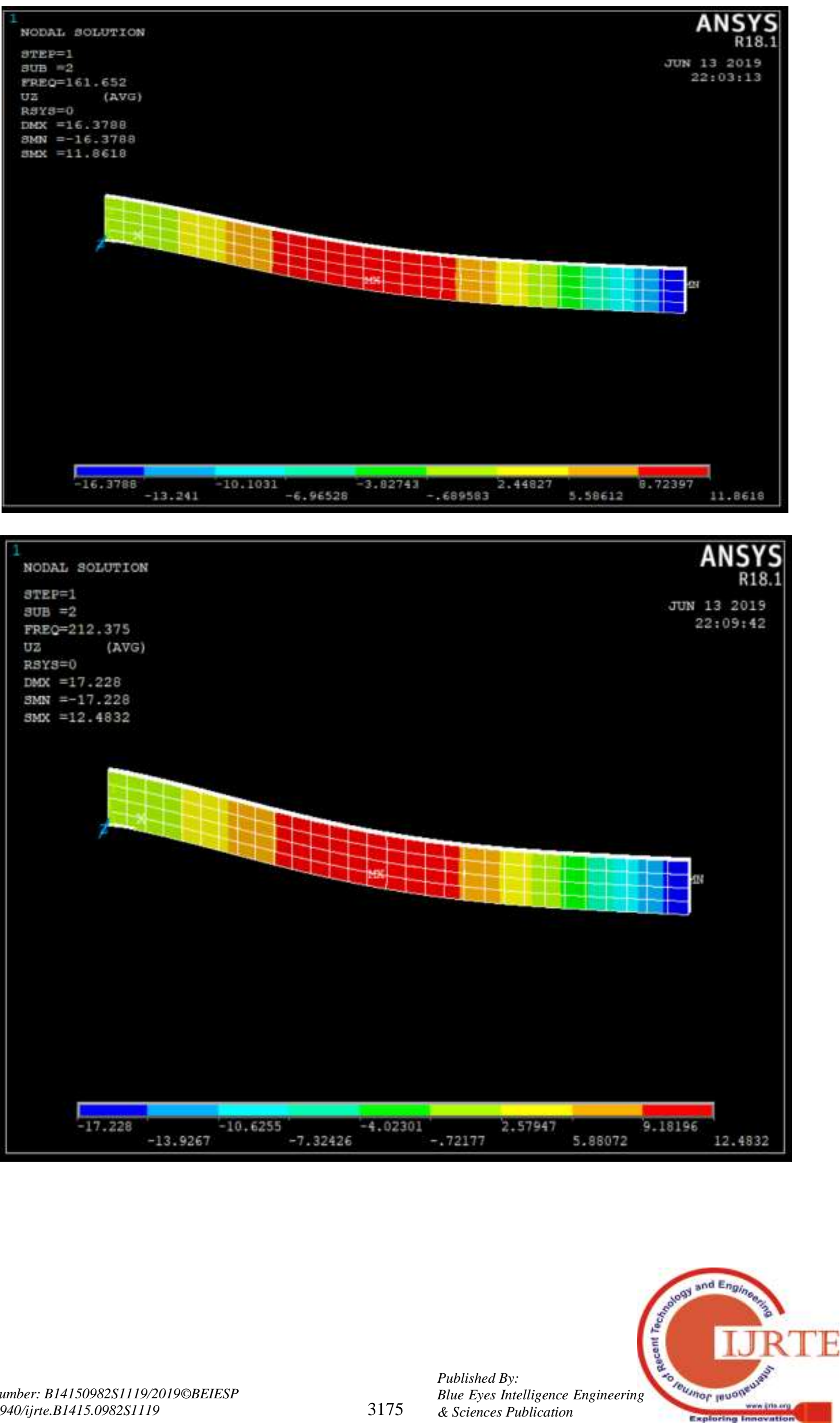
Vibration Evaluation of Laminated Hybrid Composite using Finite Element
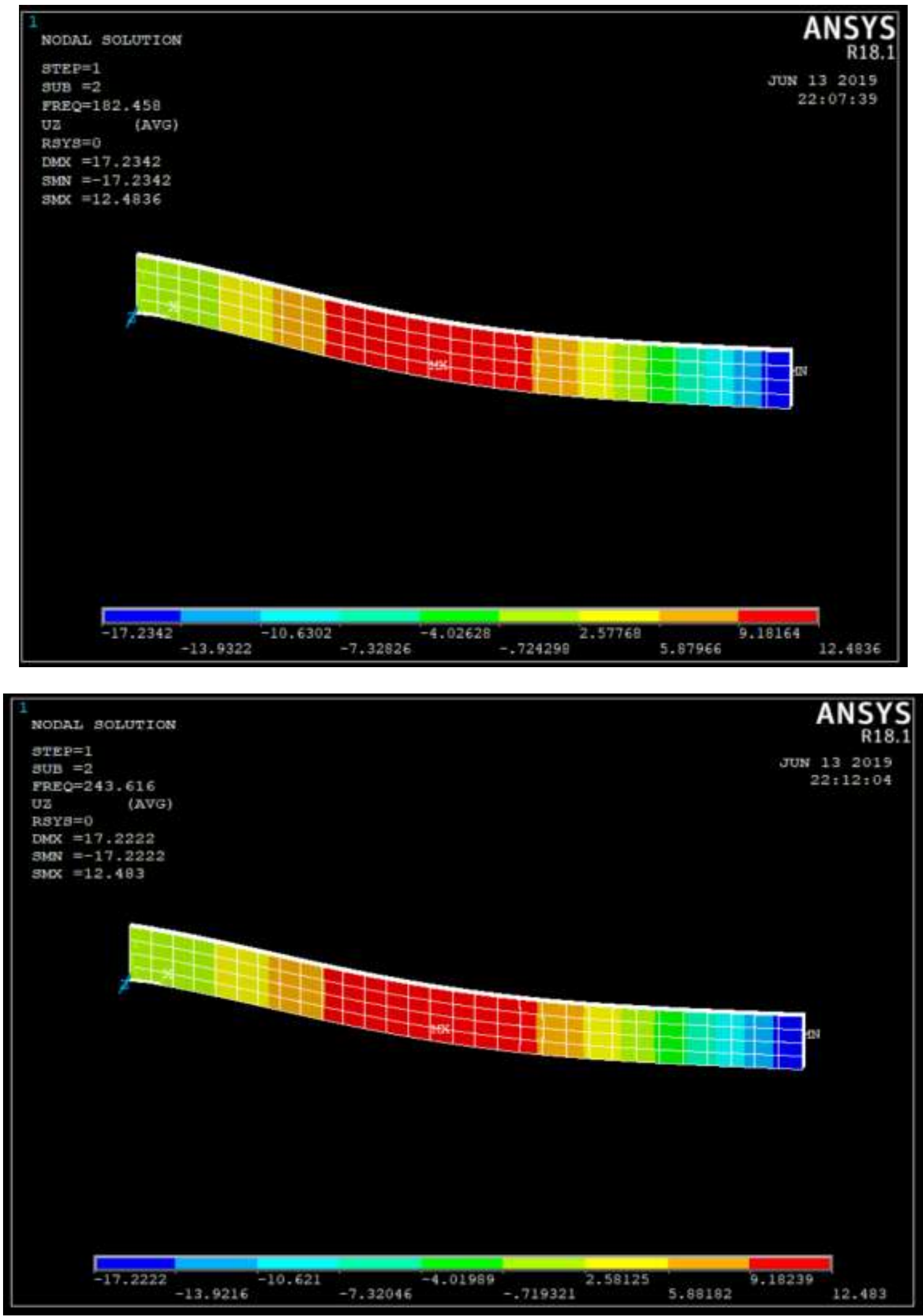

Fig. 2 Representing the Mode Shapes, Displacement and Natural Frequency of Hybrid Basalt/Carbon/Epoxy Composites.

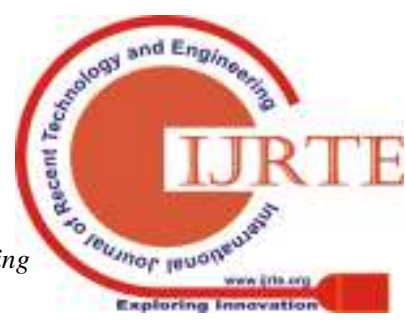




\begin{tabular}{|l|l|l|}
\hline \multirow{2}{*}{ Stacking sequence } & \multicolumn{2}{|l|}{ Natural frequency $(\mathrm{Hz})$} \\
\cline { 2 - 3 } & FEM & EXP \\
\hline CCCC & 267.1 & 270 \\
\hline BBBB & 161.6 & 160 \\
\hline CBCB & 212.3 & 225 \\
\hline BCCB & 182.4 & 158 \\
\hline CBBC & 243.6 & 242 \\
\hline
\end{tabular}

desk 3 second technique of normal recurrence of $1 / 2$ and $1 / 2$ and non-move breed covers

From the table 3 the estimations of regular recurrence are gotten from ANSYS18.1 through manner of utilizing version studies. we can say that pass breed BCCB composite example has low not unusual recurrence $182.4 \mathrm{~Hz}$ than some exceptional examples. Their mode shapes are spoken to in fig 2 .

\section{END}

in this exam, the unfastened vibration reaction of a half of of breed overlaid composites are explored. The demonstrating approach and preparations have been completed the usage of limited aspect examination programming bundle ANSYS18.1. The ends that may be drawn from the present examination are abridged as pursues. path of movement of strands effectsly have an impact on the loose vibration reaction of solidified overlaid composites which need to be taken into consideration inside the plan of hardened protected composites.

\section{REFERENCES}

1 Prasad, E. V., and S. okay. Sahu. "Vibration analysis of Woven Fiber metallic Laminated Plates-Experimental and Numerical studies." international magazine of Structural stability and Dynamics: 1850144.

2 Mishra, Itishree, and Shishir Kumar Sahu. "Modular studies of woven fiber composite plates with severa restrict conditions." worldwide magazine of Structural stability and Dynamics 15, no. 01 (2015): 1540001.

3 Mohanty, J., S. ok. Sahu, and P. okay. Parhi. "Numerical and take a look at take a look at on loose vibration of delaminated woven fiber glass/epoxy composite plates." worldwide journal of Structural balance and Dynamics 12, no. 02 (2012): 377-394.

4 four. Panda, Himanshu Sekhar, Shishir Kumar Sahu, Pravat Kumar Parhi, and Avittathur Venkiteswaran Asha. "Vibration of woven fiber composite doubly bended forums with strip delamination in warm field." journal of Vibration and control 21, no. 15 (2015): 3072-3089.

5 Faroughi, S., E. Shafei, and D. Schillinger. "Isogeometric stress, vibration and solidness research of in-aircraft overlaid composite systems." international magazine of Structural stability and Dynamics 18, no. 05 (2018): 1850070.

6 Biswal, M., S. ok. Sahu, and A. V. Asha. "Vibration of composite tube fashioned shallow shells exposed to hygrothermal stacking exploratory and numerical effects." Composites component B: Engineering 98 (2016): 108-119.

7 Chandrashekhar, M., and Ranjan Ganguli. "Nonlinear vibration investigation of composite covered and sandwich plates with abnormal cloth residences." international magazine of Mechanical Sciences fifty two, no. 7 (2010): 874-891.

8 Somireddy, Madhukar, and Amirtham Rajagopal "Meshless everyday neighbor Galerkin technique for the twisting and vibration studies of composite plates." Composite Structures111 (2014): 138-146.

9 Wang, Dongdong, and Zhenting Lin. "unfastened vibration research of flimsy plates the use of Hermite imitating bit Galerkin meshfree method with sub-region settled acclimating becoming a member of." Computational Mechanics 46, no. 5 (2010): 703-719.

10 Zhou, J. X., H. Y. Zhang, and L. Zhang. "Imitating bit molecule method for not anything and limited vibration exam." journal of sound and vibration 279, no. 1-2 (2005): 389-402.

11 Rajesh, M., Jeyaraj Pitchaimani, and N. Rajini. "loose vibration tendencies of banana/sisal regular filaments fortified half and 1/2 polymer composite shaft." Procedia Engineering one hundred forty four (2016): 1055-1059.

12 Vas, John Paul, Shreeranga Bhat, and Karthik Madhyastha. "A study on the Vibration characteristics of Bagasse-Banana Fiber Hybrid Composite." international journal of Composite substances 7, no. 5 (2017): one hundred fifty- 154 . 